\begin{tabular}{|} 
Ambiente \& Água - An Interdisciplinary Journal of Applied Science \\
ISSN 1980-993X - doi:10.4136/1980-993X \\
www.ambi-agua.net \\
E-mail: ambi-agua@agro.unitau.br
\end{tabular}

\title{
Sensibilização de professores para atuação em educação ambiental por meio da arteterapia
}

\author{
doi: 10.4136/ambi-agua.1255
}

Received: 16 Aug. 2013; Accepted: 02 Dec. 2013

\author{
Ana Stella Ribeiro Medeiros Neves ${ }^{*}$; Angela Denise Peres ${ }^{1,2}$ \\ Ana Aparecida da Silva Almeida ${ }^{1}$; Herminia Yohko Kanamura ${ }^{1,3}$ \\ ${ }^{1}$ Programa de Pós-graduação em Ciências Ambientais (PPG-CA) \\ Universidade de Taubaté, Taubaté, SP, Brasil \\ ${ }^{2}$ Secretaria de Educação do estado de São Paulo \\ ${ }^{3}$ Universidade Federal de Alfenas, Alfenas, MG, Brasil \\ *Autor correspondente: e-mail: stellaneves@gmail.com, \\ angeladperes@bol.com.br, anasilva@unitau.br, kanamura@usp.br
}

\section{RESUMO}

Tanto a Educação Ambiental (EA) quanto a Arteterapia empenham-se em promover boa qualidade de vida, tendo em comum a preocupação com as relações do homem consigo mesmo, com os outros seres vivos e com o ambiente. Este trabalho relata uma experiência sobre a aplicação de ferramentas da Arteterapia como estratégia para sensibilização de professores de uma escola municipal, para atuação em EA junto aos alunos do Ensino Fundamental. Para tanto, foram realizados cinco encontros arteterapêuticos, nos quais se buscou reflexão integrada e integradora sobre os quatro elementos da natureza, i.e, água, terra, fogo e ar, trabalhando-se com um conteúdo pensado, incorporado e refletido. Ao término da vivência em Arteterapia, e após a reflexão sobre suas amplas relações com a EA, os participantes mostraram-se abertos para novos paradigmas, podendo com isso ressignificar e mobilizar conteúdos, em busca de novas alternativas para efetiva atuação em EA.

Palavras-chave: transdisciplinaridade, quatro elementos da natureza, meio ambiente.

\section{Sensitization of teachers to act in environmental education by means of art therapy}

\begin{abstract}
Both Environmental Education (EE) and Art Therapy strive to improve quality of life by making man more aware of his relationship with himself, with other living beings and with the environment. This paper reports on the application of the tools of art therapy as a strategy to raise awareness of municipal school teachers to work in EE with elementary school children. Therefore, five art therapeutic meetings were held, in which an integrated and inclusive reflection on the four nature elements were emphasized, i.e., water, earth, fire and air, with a well thought-out and incorporated content. At the conclusion of the art therapy and after extensive reflection on the relationship with EE, participants were open to experiencing new paradigms, and could thus rethink and reorganize the curriculum, in search of new alternatives for effective EE.
\end{abstract}

Keywords: transdisciplinarity, four elements of nature, environment. 


\section{INTRODUÇÃO}

É possível entender a Educação Ambiental e a Arteterapia em um mesmo campo de atuação, com uma visão holística e sistêmica. Ambas apresentam-se como uma multiplicidade de conhecimentos e informações, com características multi, inter e transdisciplinares.

A Educação Ambiental surgiu como uma necessidade de mudança na forma de considerar o papel do ser humano no mundo, pois, à medida que ele foi se distanciando da natureza e passou a entendê-la como uma fonte infinita de recursos, que se mostravam disponíveis para serem transformados em bens consumíveis, os problemas socioambientais começaram a emergir, constituindo-se em sérias ameaças à sobrevivência do planeta Terra.

Durante muito tempo prevaleceu uma visão fragmentada, que valorizava os aspectos físico-naturais do meio ambiente, o que se refletia nos programas de Educação Ambiental, na vertente conservacionista, que tinha como foco o manejo de recursos naturais, com conteúdo baseado nas ciências biológicas. Com a percepção de que a Ecologia por si só não daria conta de reverter ou de minimizar os agravos ambientais, verificou-se a necessidade de mudanças de valores individuais e sociais que resultassem em ações de transformação da sociedade por meio da educação da população (Pelicioni e Philippi Jr, 2005). Por outro lado, é importante entender que as causas dos problemas socioambientais e de saúde envolvem aspectos culturais, econômicos, políticos, epidemiológicos, além dos ambientais e sociais, o que torna imprescindível uma compreensão integrada do meio ambiente (Toledo, 2006).

A Arteterapia pode ser entendida, de forma simplista, como a utilização de recursos artísticos em contextos terapêuticos, com o pressuposto de que o processo do fazer artístico é terapêutico e enriquecedor da qualidade de vida das pessoas (Arcuri, 2006).

De acordo com a União Brasileira das Associações de Arteterapia - UBAAT, 2011.:

A Arteterapia, que é o uso da arte como base de um processo terapêutico, propicia resultados em um breve espaço de tempo. Visa estimular o crescimento interior, abrir novos horizontes e ampliar a consciência do indivíduo sobre si e sobre sua existência. Utiliza a expressão simbólica, de forma espontânea, sem preocupar-se com a estética, através de modalidades expressivas como: pintura; modelagem; colagem; desenho; tecelagem; expressão corporal; sons; músicas; criação de personagens, dentre outras, mas utiliza fundamentalmente as artes plásticas e é isso que a identifica como uma disciplina diferenciada. Enquanto a Arte Educação ensina arte, a Arteterapia possui a finalidade de propiciar mudanças psíquicas, assim como a expansão da consciência, a reconciliação de conflitos emocionais, o autoconhecimento e o desenvolvimento pessoal.

O conceito referente ao processo arteterapêutico encontra-se, portanto, também em território comum a outras estratégias, igualmente múltiplo em sentidos e significados: cuidar, harmonizar, integrar-se à natureza (meio-ambiente), incluindo nessa visão a própria natureza psíquica, reconhecendo, por conseguinte, a interconexão entre todas as coisas (Philippini, 2010).

Para que o processo de Educação Ambiental seja efetivo, é importante fazer com que a população participe ativamente da busca de soluções para os problemas ambientais que vivencia. É necessário, para tanto, que sejam identificados quais seriam esses problemas e detectadas quais as representações que a população, nos seus diferentes segmentos, tem a respeito deles (Reigota e Santos, 2005). Entretanto, a ausência de práticas educativas focadas no olhar crítico e na emancipação dos sujeitos, com vistas à mudança de comportamento e 
atitudes, é preocupante para concretização de um dos principais objetivos da Educação Ambiental: despertar nas pessoas a capacidade crítica sobre os problemas ambientais e reforçar o sentimento de cidadania.

Nesse aspecto, a Arteterapia pode-se constituir em importante aliado da Educação Ambiental, pois ambas têm em comum a preocupação com as relações do ser humano consigo mesmo, com os outros seres vivos, seja da espécie Homo sapiens ou não, e com o ambiente que o cerca, natural ou alterado pela ação humana, e estão empenhadas em assegurar uma boa qualidade de vida na Terra. Com base em uma visão holística, ambas consideram que o indivíduo, à medida que desenvolve o autoconhecimento, estará apto a cuidar de si e do outro e será capaz de preservar a vida e o meio ambiente (Guimarães, 2010).

Em Pindamonhangaba, SP, em uma área de abrangência da microbacia do Ribeirão Grande há uma comunidade essencialmente rural, que apresenta importância do ponto de vista turístico, com restaurantes, pousadas e outros atrativos. No entanto, o local apresenta problemas sérios na questão do saneamento e tratamento dado ao esgoto (Pindamonhangaba, 2007), o que requer sensibilização e conscientização da comunidade com relação à importância da sua participação no processo de preservação da qualidade de água daquela microbacia.

Assim, no presente trabalho as ferramentas da Arteterapia foram aplicadas para capacitação de uma equipe de professores da escola do bairro Ribeirão Grande que se constituiu no primeiro passo para sensibilizar a população para as questões ambientais locais relacionadas aos recursos hídricos. A partir de então, espera-se alcançar os alunos, suas famílias e a comunidade em geral, motivando-os à construção de um projeto ambiental participativo, a ser eleito pela própria comunidade.

\section{MATERIAL E MÉTODOS}

Este trabalho foi realizado em Pindamonhangaba, município localizado no médio vale do Paraíba, no estado de São Paulo, durante o segundo semestre de 2012, tendo como objetivo capacitar e sensibilizar um grupo de professores da Escola Municipal de Ensino Fundamental Maria Apparecida Camargo de Souza, para atuação em um projeto de Educação Ambiental que está sendo implantado no bairro do Ribeirão Grande, de forma a desenvolver, nessa comunidade, capacidade crítica sobre os problemas ambientais e sociais observados no entorno, reforçando assim o sentimento de cidadania.

A localidade onde se situa a escola fica ao norte do município. A comunidade rural local convive com a natureza preservada da região, na área de abrangência da microbacia do Ribeirão Grande, uma das redes hidrográficas que descem as encostas da serra da Mantiqueira Oriental e vão desembocar na margem esquerda do rio Paraíba do Sul.

A escola é a única do bairro, de modo que ali estão matriculadas todas as crianças da região que estão em idade de cursar o ensino fundamental I. Esta foi a razão pela qual se optou pela estratégia de iniciar o trabalho nessa escola, buscando atingir, por intermédio das professoras, os alunos e os seus familiares.

O grupo, composto por seis professoras do ensino fundamental I e a gestora da escola, participou de cinco encontros arteterapêuticos, nos quais se proporcionou a reflexão integrada e integradora sobre os quatro elementos da natureza, de forma que o conteúdo não fosse apenas pensado, mas incorporado e sentido. O universo, assim como o que o permeia, é formado pelos quatro elementos, água, terra, fogo e ar, e cada um deles tem características específicas e imprescindíveis para nosso desenvolvimento. Segundo Bernardo (2008, 2009), o trabalho com recursos expressivos associados aos quatro elementos mostra-se importante para trabalhar aspectos psíquicos relacionados às quatro funções da consciência descritas por Jung: Pensamento, Sentimento, Intuição e Sensação. Ao se empreenderem estudos sobre a 
simbologia relativa aos quatro elementos, é possível correlacioná-los às quatro funções: intuição, ao fogo; sensação, à terra; pensamento, ao ar; e, sentimento, à água. Outros autores (Valladares, 2002; Wedekin, 2007) também indicaram a utilização dos quatro elementos na Arteterapia como facilitadora do processo de ensino-aprendizagem e de autoconhecimento.

Os encontros arteterapêuticos foram agendados com a gestora da escola, reservando-se para as atividades cinco dias, para horas de trabalho pedagógico coletivo (HTPC). Os encontros foram sempre às quartas-feiras, durante duas horas, das $9 \mathrm{~h} 30$ às $11 \mathrm{~h} 30$, e não contínuos, ou seja, não foram realizados em semanas seguidas, devido à necessidade que a Gestora tinha de usar o HTPC para outras finalidades de interesse da escola.

$\mathrm{Na}$ presente proposta, uma atividade de "aquecimento" foi aplicada no início de cada encontro, utilizando-se jogos cooperativos e/ou teatrais que, além de prazerosos, fortalecem vínculos sociais, como instrumento de reflexão, respeito às regras de convivência e apreço a valores morais coletivos (Afonso, 2006). Após aplicação de uma atividade arteterapêutica, exteriorizando imagens com materiais expressivos alternativos, os encontros eram finalizados com avaliação livre do processo, em uma roda de conversas, para compartilhamento de emoções/sentimentos resultantes da experiência vivenciada (Liebmann, 2000; Philippini, 2009).

No primeiro encontro, trabalhou-se o elemento TERRA e o tema "Eu comigo". Houve possibilidade de sensibilização e motivação para desenvolver o autoconhecimento, com relaxamento guiado, aplicação do jogo do espelho (Figura 1) (Liebmann, 2000, p. 156) e, como atividade arteterapêutica, a confecção de mandala utilizando materiais como argila, pedras e sementes, relacionados ao elemento terra (Figura 2) (Bernardo, 2008, p. 20).

No segundo encontro, para o elemento AR, com o tema "Eu e o outro", foram aplicados dois jogos, o das três mudanças (Spolin, 2005, A14) e o do cego e guia (Afonso, 2006, p.163), e, como atividade arteterapêutica, a confecção do olho mágico ou olho de Deus (Bernardo, 2008, p. 27), com o objetivo de contribuir para uma visão integrada da realidade, desvendando as interdependências entre o eu e o outro e as relações com o ambiente.

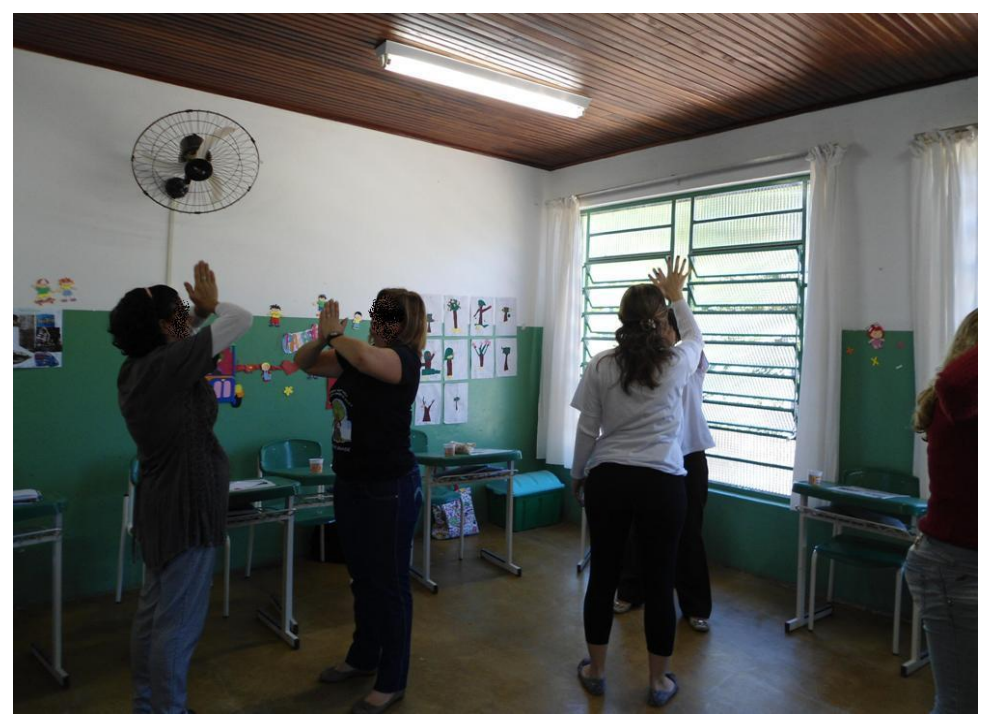

Figura 1. Professoras realizando o "Jogo do Espelho" no primeiro encontro de Arteterapia, realizado como atividade de sensibilização da equipe, em projeto de Educação Ambiental desenvolvido em escola municipal de Pindamonhangaba, SP. 




Figura 2. Mandala de argila sendo confeccionada no primeiro encontro de Arteterapia, realizado como atividade de sensibilização da equipe, em projeto de Educação Ambiental desenvolvido em escola municipal de Pindamonhangaba, SP.

No terceiro encontro, com o elemento TERRA e o tema "Eu e a comunidade", foi utilizado o jogo das ruas e vielas (Spolin, 2005, A44), e, proposta como atividade arteterapêutica, a construção de maquete com material reciclável (Figura 3) (Philippini, 2009, p. 90), com o objetivo de fortalecer a relação com o meio ambiente - "onde moro" - e reflexões sobre as causas e consequências dos problemas ambientais e sobre os valores morais e éticos inerentes à comunidade local.

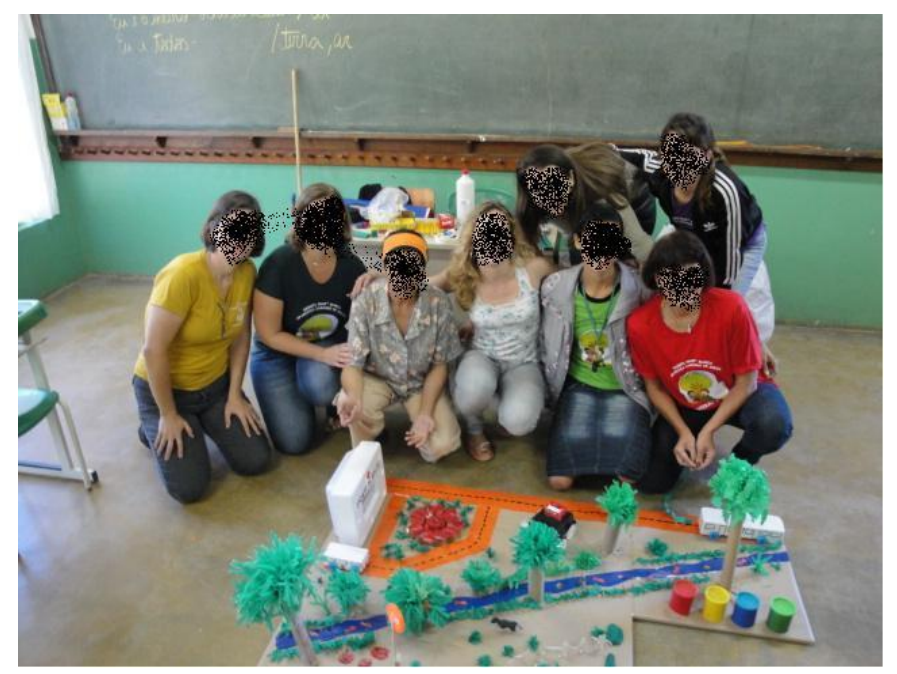

Figura 3. Professoras junto à maquete confeccionada com materiais recicláveis no segundo encontro de Arteterapia, realizado como atividade de sensibilização da equipe, em projeto de Educação Ambiental desenvolvido em escola municipal de Pindamonhangaba, SP.

O quarto encontro, com os elementos ÁGUA e FOGO, teve como atividades arteterapêuticas a elaboração de uma mandala com giz de cera derretido na chama da vela (Figura 4) (Bernardo, 2008, p. 106) e pintura invisível com vela (Figura 5) (Liebmann, 2000, p. 170). O objetivo foi propiciar ao SER um agente sustentável, conscientizado e 
conscientizador capaz de atuar na modulação de atitudes e práticas inadequadas da comunidade, sensibilizando-o para cuidar do seu próprio ambiente.

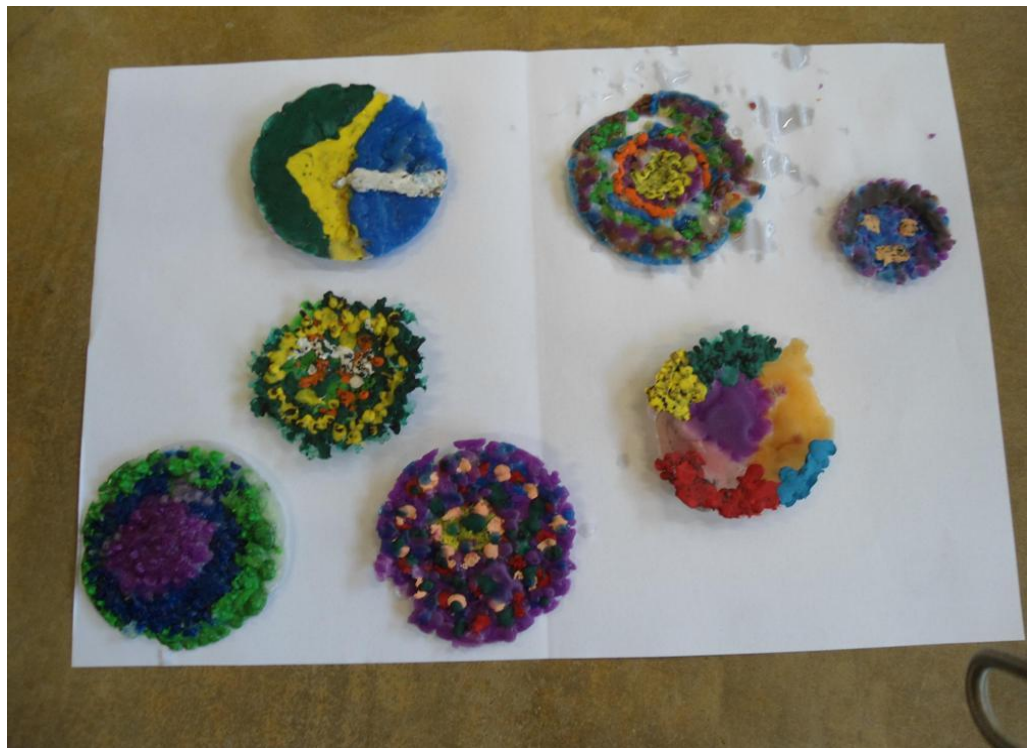

Figura 4. Mandalas de vela e giz de cera derretidos, produzidas no quarto encontro de Arteterapia, realizado como atividade de sensibilização da equipe, em projeto de Educação Ambiental desenvolvido em escola municipal de Pindamonhangaba, SP.



Figura 5. Confecção da pintura invisível durante a quarta oficina de Arteterapia, realizada como atividade de sensibilização da equipe, em projeto de Educação Ambiental desenvolvido em escola municipal de Pindamonhangaba, SP.

Como quinto e último encontro, foi proposta uma vivência, com apresentação da história "Romeu e Julieta", de autoria de Ruth Rocha, para trabalhar como seria a percepção do mundo por meio de uma única cor, ou seja, de um único ponto de vista. Discutiu-se sobre a necessidade de se estar aberto para ouvir, sentir e entender as diferentes percepções do mesmo fato ou problema, conforme experiências e histórias de vida já vivenciadas. Após a roda de conversas, com compartilhamento de emoções e sentimentos resultantes da vivência, foi solicitado às participantes desse último encontro que elaborassem um trabalho (Figura 6), para 
representar o processo resultante da experiência dos cinco encontros arteterapêuticos, primeiro na forma de uma imagem e, depois, de um texto escrito.

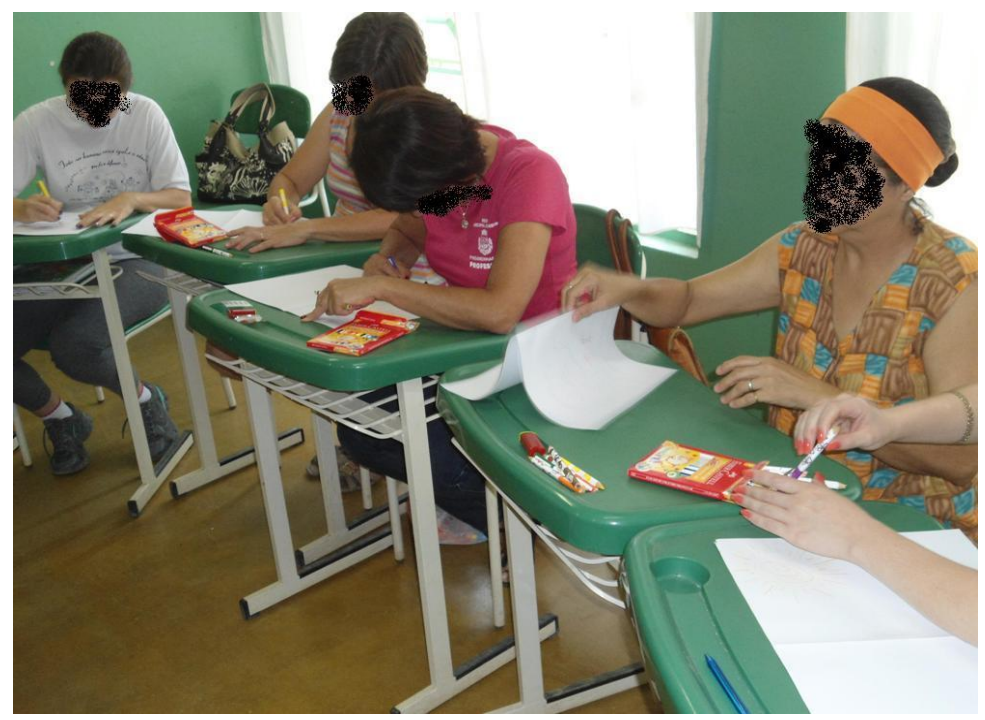

Figura 6. Elaboração de imagens e textos resultantes do processo de transformação no quinto e último encontro de Arteterapia, realizado como atividade de sensibilização da equipe, em projeto de Educação Ambiental desenvolvido em escola municipal de Pindamonhangaba, SP.

Este estudo constitui parte do projeto de pesquisa intitulado "Educa a gente: Educação Ambiental como estratégia para a melhoria das condições de saneamento e de qualidade de vida", que teve aprovação do Comitê de Ética em Pesquisa da Universidade de Taubaté (protocolo CEP/UNITAU No 265/10).

\section{RESULTADOS E DISCUSSÃO}

Após conhecer a proposta do projeto, as professoras dispuseram-se a participar das atividades de Arteterapia, por meio das quais ocorreria o processo de sensibilização, com a finalidade de receber capacitação para atuar com os alunos da escola. Todas elas participaram do encontro no qual se trabalhou o elemento TERRA, quando se aplicou, como atividade arteterapêutica, a confecção de mandala de argila, pedras e sementes. Nos demais houve uma falta por encontro, por questões de saúde, o que não prejudicou a aplicação da metodologia, tampouco refletiu nos resultados observados. Por conta de terem sido utilizados os horários de HTPC das professoras, não foi possível estabelecer uma sequência regular de encontros, de modo que eles foram realizados quinzenalmente ou em intervalos maiores, dependendo do cronograma de reuniões da escola. Tal fato pode ser enxergado como positivo na medida em que proporcionou tempo suficiente para reflexão entre uma prática e outra, permitindo a entronização dos novos paradigmas aprendidos. O tempo cedido para a prática, cerca de duas horas por encontro, referente ao tempo de HTPC, muitas vezes foi ainda menor, devido a atrasos, e mostrou-se insuficiente para a aplicação de todas as técnicas inicialmente planejadas, mas o resultado final não se mostrou prejudicado.

Algumas das imagens produzidas no último encontro (Figura 7) indicam mudanças observadas pelos participantes durante a vivência com a Arteterapia. As imagens da esquerda representam o "antes", e as da direita, o "depois" das vivências em Arteterapia. É possível observar, de maneira geral, um esboço mais simples no primeiro momento, e, no segundo, uma figura mais elaborada, com mais cores e detalhes, sugerindo que alguns canais se abriram durante o processo. 


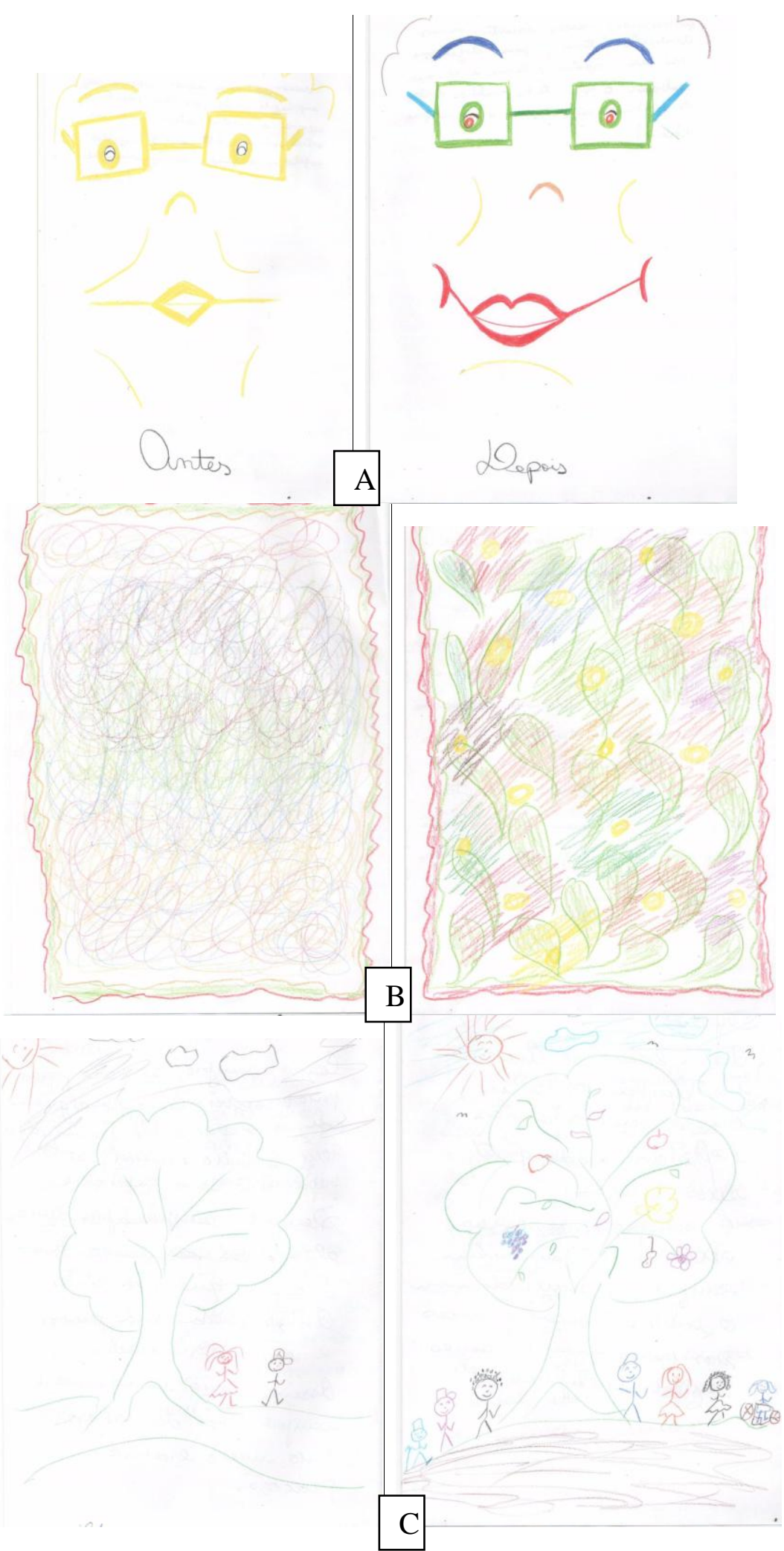

Figura 7. Desenhos que representam o "antes" e o "depois" do processo arteterapêutico, produzidos no quinto encontro por três das professoras (A, B e C) que participaram das atividades de Arteterapia realizadas como processo de sensibilização da equipe, em projeto de Educação Ambiental desenvolvido em escola municipal de Pindamonhangaba, SP. 
Os textos elaborados pelas participantes no quinto encontro representam a síntese dos sentimentos e percepções resultantes dessa experiência com Arteterapia, aplicada durante o processo de sensibilização de uma equipe para atuação em Educação Ambiental.

Os seguintes textos foram selecionados dentre os vários apresentados:

Se for analisar todos os passos percorridos nesses encontros, nessas avaliações internas, posso dizer que saí da apatia interna e consegui sobrepor o que tenho melhor dentro de minha pessoa, que é a alegria. Valeu! (da professora que produziu a imagem representada na figura 7-A).

Como tudo se transforma, houve em nós, comunidade, em mim, pessoa, a certeza deste dito. A passividade, a falta de perspectiva de antes, apesar do não conhecimento disto e hoje o florescer de conhecimentos, com certeza fará a diferença (da professora que produziu a imagem representada na figura 7-B).

Assim como a árvore no tempo certo nos dá os seus aromas, frutos e sua beleza. E sempre que pessoas recebem e transmitem sempre se multiplica o saber. E assim vocês nos passaram e vamos sempre multiplicar (da professora que produziu a imagem representada na figura $7-\mathrm{C}$ ).

Os sentimentos, descritos nos textos dos participantes, após a vivência com as oficinas de Arteterapia, vêm ao encontro das observações de Urrutigaray (2003, p. 27):

Como instrumento educativo, a Arteterapia, pela essência de sua ação terapêutica, pode possibilitar atividades preventivas tanto no âmbito psicopedagógico, já que oferece uma interação entre arte e cognição, quanto no contexto de re-significações de atitudes pessoais. Em ambas as situações a aprendizagem encontra-se presente. Pois nelas podem ser vislumbradas, como condição dada pela arte, a objetivação de algo que torna as ações possíveis de introspecção e reflexão, oferecendo elementos para o crescimento e desenvolvimento. Ou seja, mobilizando a construção pessoal a partir da utilização de técnicas específicas da Arteterapia, temos a aprendizagem como resultado deste processo, seja na educação sistematizada, pela formalidade e diretriz presente na instituição escolar, ou em outros eventos modeladores de comportamentos.

O processo de sensibilização da equipe mostrou-se complexo e dinâmico. Notava-se, no início, certa resistência, que foi sendo rompida na medida em que a prática promovia reflexões e mostrava caminhos antes não percebidos. A percepção da importância de cada participante nas atividades foi explicitada por meio dos princípios da autonomia, continuidade, participação e cooperação, princípios que a ação educativa ambiental exige no decorrer de suas atividades.

Após analisar o processo desenvolvido no presente trabalho, os participantes estavam mais motivados e envolvidos com as atividades propostas, despertando para aceitar novos desafios. Tais mudanças foram internas, mas se externalizaram nos desenhos e textos apresentados pelas participantes, no quinto e último encontro dessa etapa do Projeto de Educação Ambiental. Também ocorreram mudanças significativas na atuação das educadoras dentro da escola, que passaram a apresentar atitudes pró-ativas relacionadas à questão ambiental, promovendo melhorias no ambiente escolar, como a revitalização do jardim e atividades extraclasse, como uma caminhada ecológica e trabalhos de desenho e confecção de maquetes, com os alunos. 
Finalizada a capacitação, com fundamento na resposta da equipe, que se tornou mais compromissada, sensível às questões ambientais locais e solícita quanto aos próximos passos, verificou-se que o emprego da Arteterapia como processo de sensibilização e conscientização mostrou-se fundamental para garantir o sucesso do projeto. Isso porque era necessário e imprescindível criar nessa equipe o compromisso com a prática educativa, que valoriza a participação das pessoas nas comunidades onde o projeto está sendo implantado, percebendoas, não só como "objetos" de estudo ou como simples "depositários" de conhecimentos, mas como elementos capazes de pôr em prática os conceitos e temas discutidos em grupo. Conforme Thiollent (2000) e Tonzoni-Reis (2005), a pesquisa-ação, enquanto modalidade de pesquisa associada a diversas formas de ação coletiva, é orientada em função da resolução de problemas, com objetivos de transformação.

Com essas orientações, como recurso para sensibilizar a população da comunidade na qual o Projeto está sendo implantado, foi empreendida esta etapa de sensibilização e capacitação das professoras, tendo em vista as características e os problemas socioambientais encontrados nessa comunidade de Pindamonhangaba.

Assim, para que as educadoras pudessem se abrir para um novo paradigma era necessário também que o vivenciassem, para que pudessem incorporar os conteúdos trabalhados, na busca de alternativas. A Arteterapia, utilizando como temas para os encontros os quatro elementos da natureza, apresentou-se como uma ferramenta eficiente para esse fim, podendose indicar sua utilização também para a sensibilização das comunidades a serem mobilizadas, no Projeto de Educação Ambiental em questão.

\section{CONSIDERAÇÕES FINAIS}

Foi notória a satisfação e a superação coletiva e pessoal de cada participante nos jogos e nas atividades arteterapêuticas. A Arteterapia foi um instrumento facilitador para livre expressão, não se restringindo apenas ao valor estético do produto final; pelo contrário, valorizou o processo, que possibilitou às participantes a expressão e a comunicação de suas idéias e percepções. Contribuíram nessas aplicações o interesse e respeito pela obra e opinião do outro, e também o desenvolvimento da autonomia e de atitudes de autoconfiança em relação às produções pessoais, além do fortalecimento dos vínculos de equipe. Vale ressaltar que, com as vivências, o grupo passou à reflexão de como aliar Educação Ambiental a Arteterapia para se conseguir a transformação comportamental na comunidade onde se pretende trabalhar, e de como essas vivências poderiam contribuir na conscientização ambiental.

As oficinas arteterapêuticas mostraram-se, portanto, eficientes ferramentas, que proporcionaram reflexão e as mudanças necessárias para que as participantes se abrissem para novos paradigmas, podendo com isso sentir, incorporar, ressignificar e mobilizar os conteúdos em busca de alternativas para uma efetiva atuação em Educação Ambiental.

\section{AGRADECIMENTOS}

Ao Fundo Estadual de Recursos Hídricos - FEHIDRO, pelo aporte financeiro, e à arteterapeuta Elisabeth Corregiari de Siqueira Costa, pelo trabalho nas oficinas de Arteterapia.

\section{REFERÊNCIAS}

AFONSO, M. L. M. Oficinas em dinâmica de grupo: um método de intervenção psicossocial. São Paulo: Casa do Psicólogo, 2006.

ARCURI, I. G. Arteterapia: um novo campo de conhecimento. São Paulo: Vetor, 2006. 
BERNARDO, P. P. A prática da arteterapia: correlações entre temas e recursos, volume I: temas centrais em arteterapia. São Paulo: Autor, 2008.

BERNARDO, P. P. A prática da arteterapia: correlações entre temas e recursos, volume II: mitologia indígena e arteterapia: a arte de trilhar a roda da vida. São Paulo: Autor, 2009.

GUIMARÃES, G. N. Arteterapia na ecologia humana: a busca da sustentabilidade emocional e socioambiental. CONGRESSO BRASILEIRO DE ARTETERAPIA, 9., 2010. Arteterapia no século XXI: diversidade e profissionalização. São Paulo: Associação de Arteterapia do Estado de São Paulo, 2010. p. 117-122.

LIEBMANN, M. Exercícios de arte para grupos: um manual de temas, jogos e exercícios. Tradução de Rogério Migliorini. São Paulo: Summus, 2000.

PELICIONI, M. C. F.; PHILIPPI Jr, A. Bases políticas, conceituais, filosóficas e ideológicas da educação ambiental. In: PHILIPPI JÚNIOR, A.; PELICIONI, M. C. F. (editores). Educação ambiental e sustentabilidade. Barueri: USP, 2005. p. 3-12. (Ambiental, 3).

PHILIPPINI, A. Linguagens e materiais expressivos em arteterapia: uso, indicações e propriedades. Rio de Janeiro: Wak, 2009.

PHILIPPINI, A. Interfaces entre arteterapia, ecologia profunda e eco arte. In: CONGRESSO BRASILEIRO DE ARTETERAPIA, 9., 2010. Arteterapia no século XXI: diversidade e profissionalização. São Paulo: Associação de Arteterapia do Estado de São Paulo, 2010. p. 114-116.

PINDAMONHANGABA. Prefeitura. As condições sanitárias nas sub-bacias hidrográficas do Ribeirão Grande e Piracuama e o comprometimento da qualidade da água: diagnóstico ambiental e proposta de ações de controle. Projeto apresentado ao Fundo Estadual de Recursos Hídricos - FEHIDRO. Relatório Final. Pindamonhangaba, 2007.

REIGOTA, M.; SANTOS, R. F. Responsabilidade social da gestão e uso dos recursos naturais: o papel da educação no planejamento ambiental. In: PHILIPPI JÚNIOR, A.; PELICIONI, M. C. F. (editores). Educação ambiental e sustentabilidade. Barueri: USP, 2005. p. 849-863. (Ambiental, 3).

SPOLIN, V. Improvisação para o teatro. São Paulo: Perspectiva, 2005.

THIOLlENT, M. Metodologia da pesquisa-ação. 2. ed. São Paulo: Cortez, 2000.

TOLEDO, R. F. Educação, saúde e meio ambiente: uma pesquisa-ação no Distrito de Iauaretê do município de São Gabriel da Cachoeira, AM. 2006. 329f. Tese (Doutorado em Saúde Pública) - Faculdade de Saúde Pública, Universidade de São Paulo, São Paulo, 2006.

TOZONI-REIS, M. F. C. Pesquisa-ação: compartilhando saberes. Pesquisa e ação educativa ambiental. In: FERRARO JR., L. A. (Org.). Encontros e caminhos: formação de educadoras(es) ambientais e coletivo educadores. Brasília: Ministério do Meio Ambiente, 2005. Disponível em: <http://www.mma.gov.br/port/sdi/ea/og/pog/arqs/encontros.pdf>. Acesso em: 09 set. 2011.

UNIÃO BRASILEIRA DAS ASSOCIAÇÕES DE ARTETERAPIA - UBAAT. Histórico da arteterapia. Disponível em: 〈http://www.ubaat.org>. Acesso em: 17 jun. 2011.

URRUTIGARAY, M. C. Arteterapia: a transformação pessoal pelas imagens. Rio de Janeiro: Wak, 2003. 
VALLADARES, A. C. A. A Arteterapia e a tipologia de Jung: uma experiência abordando os quatro elementos da natureza. Rev. Arteterapia: Imagens da Transformação. Rio de Janeiro, v. 9, n. 9, p. 35-50, 2002.

WEDEKIN, L. M. Reflexões sobre os significados dos quatro elementos na arteterapia. RECNA, p. 16-32, maio 2007. 